\title{
A randomised trial to evaluate the immunogenicity, reactogenicity, and safety of the 10-valent pneumococcal non-typeable Haemophilus influenzae protein D conjugate vaccine (PHiD-CV) co-administered with routine childhood vaccines in Singapore and Malaysia
}

Fong Seng Lim", Mia Tuang Koh ${ }^{2}$, Kah Kee Tan ${ }^{3}$, Poh Chong Chan ${ }^{4 \dagger}$, Chia Yin Chong ${ }^{5 \dagger}$, Yeo Wee Shung Yehudi ${ }^{1}$, Yee Leong Teoh ${ }^{6,7}$, Fakrudeen Shafi ${ }^{8}$, Marjan Hezareh ${ }^{9}$, Kristien Swinnen ${ }^{9}$ and Dorota Borys ${ }^{9}$

\begin{abstract}
Background: The immunogenicity, reactogenicity, and safety of the 10-valent pneumococcal non-typeable Haemophilus influenzae protein D conjugate vaccine (PHiD-CV) co-administered with routine childhood vaccines were evaluated among infants from Singapore and Malaysia, where PHiD-CV has been licensed.
\end{abstract}

Methods: In the primary vaccination phase, 298 infants from Singapore and 168 infants from Malaysia were randomised to receive the Phase III Clinical (Clin) or the Commercial (Com) lot of PHiD-CV at 2, 3, and 5 months of age. In the booster vaccination phase, 238 toddlers from Singapore received one dose of the PHiD-CV Commercial lot at 18-21 months of age. Immune responses to pneumococcal polysaccharides were measured using 22F-inhibition enzyme-linked immunosorbent assay (ELISA) and functional opsonophagocytic activity (OPA) assay and to protein D, using ELISA.

Results: Immune responses induced by primary vaccination with the PHiD-CV Commercial lot were non-inferior to the Phase III Clinical lot in terms of adjusted antibody geometric mean concentration (GMC) ratios for each vaccine pneumococcal serotype and protein D. For each vaccine pneumococcal serotype, $\geq 93.6 \%$ and $\geq 88.5 \%$ of infants from Malaysia and Singapore had post-primary vaccination antibody concentrations $\geq 0.2 \mu \mathrm{g} / \mathrm{mL}$ and OPA titres $\geq 8$, in the Clin and Com groups, respectively. For each vaccine pneumococcal serotype, $\geq 60.8 \%$ and $\geq 98.2 \%$ of toddlers from Singapore had pre- and post-booster antibody concentrations $\geq 0.2 \mu \mathrm{g} / \mathrm{mL}$, in the Clin and Com groups, respectively. All children, except one, had measurable anti-protein $\mathrm{D}$ antibodies and the primary and booster doses of the co-administered vaccines were immunogenic. The incidence of each grade 3 solicited symptom was $\leq 11.1 \%$ in both study phases. No serious adverse events considered causally related to vaccination were reported throughout the study.

Conclusions: PHiD-CV given as three-dose primary vaccination to infants in Singapore and Malaysia and booster vaccination to toddlers in Singapore was shown to be immunogenic with a clinically acceptable-safety profile. This study has been registered at www.clinicaltrials.gov NCT00808444 and NCT01119625.

Keywords: Pneumococcal conjugate vaccine, Immunogenicity, Safety, Non-typeable Haemophilus influenzae, Infant, Toddler, Singapore, Malaysia

\footnotetext{
*Correspondence: fong_seng_lim@nhgp.com.sg

${ }^{\dagger}$ Equal contributors

'National Healthcare Group Polyclinics, 3 Fusionopolis Link \#03-08, Nexus@one-north, Singapore 138543, Singapore

Full list of author information is available at the end of the article
} 


\section{Background}

Streptococcus pneumoniae is responsible for invasive diseases, which cause significant morbidity and mortality worldwide [1]. The incidence of invasive pneumococcal disease (IPD) is especially high in Asia, where children younger than 5 years old are the most severely affected [2-5]. In Singapore, the incidence of IPD reached 15.2 per 100,000 children <5 years of age in 2008-2010; the most common serotypes were serotypes 6B, 19A, 14, and 23F [6]. In Malaysia, there is limited information on the incidence of IPD, although a previous study suggested that the incidence of pneumococcal meningitis reached 8.6 per 100,000 children $<5$ years of age in 2004-2006 [7]. The most common serotypes in Malaysia in 2008-2009 were serotypes 19F, 6B, 19A, and 14 [6,8]. In both countries, emergence of antimicrobial resistant $S$. pneumoniae isolates is a major health concern [3,8-14].

Prevention of pneumococcal infections through vaccination remains the best strategy to reduce the incidence of IPD. A 10-valent pneumococcal non-typeable Haemophilus influenzae (NTHi) protein D conjugate vaccine (PHiD-CV; Synflorix ${ }^{\mathrm{Tm}}$, GlaxoSmithKline Vaccines), which contains serotypes 1, 4, 5, 6B, 7F, 9V, 14, 18C, 19F, and 23F, was licensed in Singapore in March 2010 and in Malaysia in September 2009. PHiD-CV has been shown to be immunogenic and well-tolerated when co-administered with commonly used paediatric vaccines in infants and toddlers [15-22]. Since eight of the ten pneumococcal serotypes included in PHiD-CV are conjugated to NTHi protein $\mathrm{D}$, this vaccine has the potential to provide additional protection against NTHi diseases [23].

This study compared the immunogenicity, reactogenicity, and safety of three-dose primary vaccination with a Phase III Clinical lot or a Commercial lot of PHiD-CV co-administered with routine childhood vaccines in infants from Singapore and Malaysia. The immunogenicity and safety of a booster dose of the PHiD-CV Commercial lot were also evaluated in toddlers from Singapore.

\section{Methods}

\section{Study design}

This Phase III study comprised a primary vaccination phase conducted in three centres in Singapore and two centres in Malaysia between January 2009 and November 2009 , and a booster vaccination phase conducted in the three Singaporean centres between July 2010 and February 2011. The booster vaccination phase did not encompass Malaysia since PHiD-CV obtained registration in Malaysia in September 2009 and booster vaccination could thus be offered outside clinical trial settings.

In the primary vaccination phase, infants were randomised (1:1) to two parallel groups to receive three doses of the PHiD-CV Phase III Clinical (Clin group) or Commercial lot (Com group) at 2, 3, and 5 months of age.
PHiD-CV was co-administered with diphtheria, tetanus, acellular pertussis-hepatitis B virus-inactivated poliovirus, and $H$. influenzae type b vaccine (DTPa-HBV-IPV/Hib) in Malaysia at 2, 3, and 5 months of age and in Singapore at 2 and 5 months of age and with DTPa-IPV/Hib in Singapore at 3 months of age. All infants received two doses of a human rotavirus (HRV) vaccine at 2 and 3 months of age. The primary vaccination phase was double-blinded.

In the booster vaccination phase, all toddlers from Singapore received a booster dose of the PHiD-CV Commercial lot co-administered with DTPa-IPV/Hib at 18-21 months of age. Thus, the booster vaccination phase was conducted in an open-label manner.

The study was conducted in accordance with Good Clinical Practice guidelines and the Declaration of Helsinki. The protocol and associated documents were reviewed and approved by the Medical Research \& Ethics Committee of the Ministry of Health in Malaysia and the Medical Ethics Committee of University Malaya Medical Centre and the Domain-Specific Review Board of the National Healthcare Group in Singapore. Written informed consent was obtained before enrolment from the parents or legally acceptable representatives of each child. This study has been registered at www.clinicaltrials.gov NCT00808444 and NCT01119625. A protocol summary is available at http://www.gsk-clinicalstudyregister.com (GSK study IDs 111654 and 113266).

\section{Study objectives}

The primary objectives were to demonstrate the comparability of the immune response induced by three-dose primary vaccination with the Commercial lot versus the Phase III Clinical lots of PHiD-CV in infants from Malaysia and Singapore, and to assess the persistence of the antibodies induced by both PHiD-CV lots up to the booster vaccination in toddlers from Singapore. Secondary objectives included the evaluation of the immunogenicity, safety, and reactogenicity of $\mathrm{PHiD}-\mathrm{CV}$ and the co-administered vaccines after primary and booster vaccinations.

\section{Study participants}

Eligible participants were healthy infants from Malaysia and Singapore aged 6-12 weeks at the time of the first vaccination, who were born after a gestation period of between 36 and 42 weeks. For the booster vaccination phase, eligible participants were healthy toddlers aged 18-21 months at the time of the booster vaccination, who had received three $\mathrm{PHiD}-\mathrm{CV}$ doses in the primary vaccination phase in Singapore.

Children were excluded from participation if they were concurrently participating in another clinical study; were immunosuppressed; had used investigational products within 30 days pre-vaccination; had previously received 
blood products; had previous vaccination against or history of diphtheria, tetanus, pertussis, poliomyelitis, hepatitis B, Hib, or pneumococcal disease; or had allergic disease or reactions likely to be exacerbated by the vaccines, history of neurological disorders or seizures, major congenital defects, or a serious chronic illness.

\section{Vaccines}

The Commercial and Phase III Clinical lots of PHiD-CV had the same composition, which has been previously described [21]. They were administered intramuscularly in the right thigh in infants and the right deltoid or thigh in toddlers. All co-administered vaccines were manufactured by GlaxoSmithKline Vaccines. DTPa-IPV/Hib (Infanrix $\left.{ }^{\text {тм }}-\mathrm{IPV} / \mathrm{Hib}\right)$ and DTPa-HBV-IPV/Hib (Infanrix ${ }^{\text {тм }}$ hexa) were administered intramuscularly in the left thigh in infants and the left deltoid or thigh in toddlers. The live attenuated HRV vaccine (Rotarix ${ }^{\mathrm{TM}}$ ) was administered orally.

\section{Immunogenicity assessment}

Blood samples were collected one month post-primary vaccination and before and one month after the booster vaccination. Antibody concentrations against vaccine pneumococcal serotypes and cross-reactive serotypes were measured by 22F-inhibition enzyme-linked immunosorbent assay (ELISA) as described previously (cut-off: $0.05 \mu \mathrm{g} / \mathrm{mL}$ ) [24,25]. Percentages of children with antibody concentrations $\geq 0.2 \mu \mathrm{g} / \mathrm{mL}$ were determined. Antibody concentrations of $0.2 \mu \mathrm{g} / \mathrm{mL}$ measured by $22 \mathrm{~F}$-inhibition ELISA are equivalent to antibody concentrations of $0.35 \mu \mathrm{g} / \mathrm{mL}$ measured by the World Health Organization reference ELISA without 22F-inhibition, which is the threshold used for comparisons of immune responses induced by different pneumococcal conjugate vaccines $[25,26]$. In the primary vaccination phase, opsonophagocytic activity (OPA) was measured by a pneumococcal killing assay using a HL 60 cell line (cut-off titre: 8) $[27,28]$. Antibodies against NTHi protein D were measured by an in-house ELISA using a recombinant non-lipidated form of protein D as coating material. Anti-protein D antibodies, which are bound to protein $\mathrm{D}$ antigens adsorbed on polystyrene plates, are detected using an anti-humanIgG peroxidase labelled antibody followed by the addition of tetramethylbenzidine substrate. Anti-protein D antibody concentrations were expressed in ELISA units per $\mathrm{mL}$ (EL.U/mL), and the assay cut-off was $100 \mathrm{EL} . \mathrm{U} / \mathrm{mL}$.

Infants were sub-randomised $(1: 1)$ to two subsets for the analysis of immune responses to co-administered vaccines. Immune responses were measured by ELISA [29-34], except for the three poliovirus types, which were measured by a virus microneutralisation test [35]. All laboratory analyses were performed at GlaxoSmithKline (Rixensart, Belgium) or in laboratories designated by
GlaxoSmithKline Vaccines. Upon discovery of an antihepatitis B assay specificity issue, a risk was identified that children whose post-vaccination titres were initially measured between 10 and $100 \mathrm{mIU} / \mathrm{mL}$ might have been informed of an incorrect seroprotection status. Retesting was performed as an urgent precaution using Immulite ${ }^{\mathrm{Tx}}$, a commercial assay used for routine testing at Ghent University Hospital, Belgium.

\section{Safety and reactogenicity assessment}

Solicited local (injection sites pain, redness, and swelling) and general (irritability, drowsiness, fever [rectal/axillary temperature $\geq 38.0^{\circ} \mathrm{C} / 37.5^{\circ} \mathrm{C}$ ], and loss of appetite) symptoms and antipyretic use were recorded during a four-day post-vaccination period. In the primary vaccination phase, vomiting and diarrhoea were also recorded for four days post-vaccination. Unsolicited adverse events (AEs) were recorded for 31 days post-vaccination. The intensity of each symptom was graded on a three-grade scale. Grade 3 was reported for pain if infants/toddlers cried when the limbs were moved or if the limbs were spontaneously painful; redness and swelling, if diameters were $>30 \mathrm{~mm}$; fever, if rectal/axillary temperature was $>40.0^{\circ} \mathrm{C} / 39.5^{\circ} \mathrm{C}$; loss of appetite, if infants/toddlers did not eat at all; irritability, if infants/toddlers cried and could not be comforted; diarrhoea, if infants had $\geq 6$ looser than normal stools/day; vomiting, if infants had $\geq 3$ episodes/day; and all other AEs, if they prevented normal activity.

Serious adverse events (SAEs) were recorded throughout the study and were defined as events that were lifethreatening, required hospitalisation or prolongation of hospitalisation, or resulted in disability, incapacity, or death. As per protocol, all solicited local symptoms were considered causally related to vaccination. Causality of all other AEs was assessed by investigators.

\section{Statistical analyses}

Safety analyses were performed on the primary and booster total vaccinated cohorts. Immunogenicity analyses were performed on the primary and booster according-toprotocol (ATP) immunogenicity cohorts and on the ATP persistence cohort, which included all infants/ toddlers who met all eligibility criteria, complied with protocol-defined procedures, and for whom antibody assay results were available.

Antibody geometric mean concentrations (GMCs), OPA geometric mean titres (GMTs), and percentages of infants/ toddlers with concentrations or titres above pre-specified cut-offs/thresholds were calculated with 95\% confidence intervals (CIs). GMCs and GMTs were calculated by taking the anti-log of the mean of the log antibody concentration/ titre transformations. Antibody concentrations/titres below 
assay cut-offs were given an arbitrary value of half the cut-off.

Non-inferiority of the Commercial versus the Phase III Clinical lot was demonstrated if the upper limit (UL) of the two-sided 95\% CI (calculated using an ANOVA model [pooled variance] adjusting for multi-country effect) on adjusted GMC ratios (Clin over Com group) for antibodies against vaccine pneumococcal serotypes and protein $\mathrm{D}$ was below 2 .

In the primary vaccination phase, the target sample size was 460 enrolled infants to obtain $\geq 400$ evaluable infants. When comparing both PHiD-CV lots, 200 evaluable infants per group would provide at least $98 \%$ power under equal mean or $85 \%$ power in case of 1.2 -fold decrease in GMCs to show non-inferiority of the Commercial lot compared to the Phase III Clinical lot with respect to adjusted antibody GMC ratios for vaccine pneumococcal serotypes and protein $\mathrm{D}$. In the booster vaccination phase, the target sample size was 298 enrolled toddlers, taking into account the actual enrolment in the primary vaccination phase in Singapore.

Incidences of solicited and unsolicited AEs were calculated with exact 95\% CIs. SAEs and withdrawals due to AEs were described in detail. Non-overlapping two-sided
95\% CIs were used to highlight potential group differences, which should be interpreted with caution.

Statistical analyses were performed using Statistical Analysis System $\left(\mathrm{SAS}^{\bullet}\right.$ software, SAS Institute Inc., Cary, NC, United States) version 9.2 and SDD (i.e. SAS Drug and Development) web portal version 3.5.

\section{Results}

\section{Study population}

A total of 466 infants were enrolled and 464 infants completed the primary vaccination phase (Figure 1). 238 toddlers from Singapore were included in the booster vaccination phase and 231 toddlers completed the study. The demographic characteristics of the infants included in the primary ATP immunogenicity cohort were comparable in both groups and were consistent with those of the toddlers from Singapore included in the booster ATP immunogenicity cohort (Table 1).

\section{Immunogenicity}

\section{Pneumococcal vaccine antigens}

In the primary vaccination phase, immune responses induced by the PHiD-CV Commercial lot were shown to

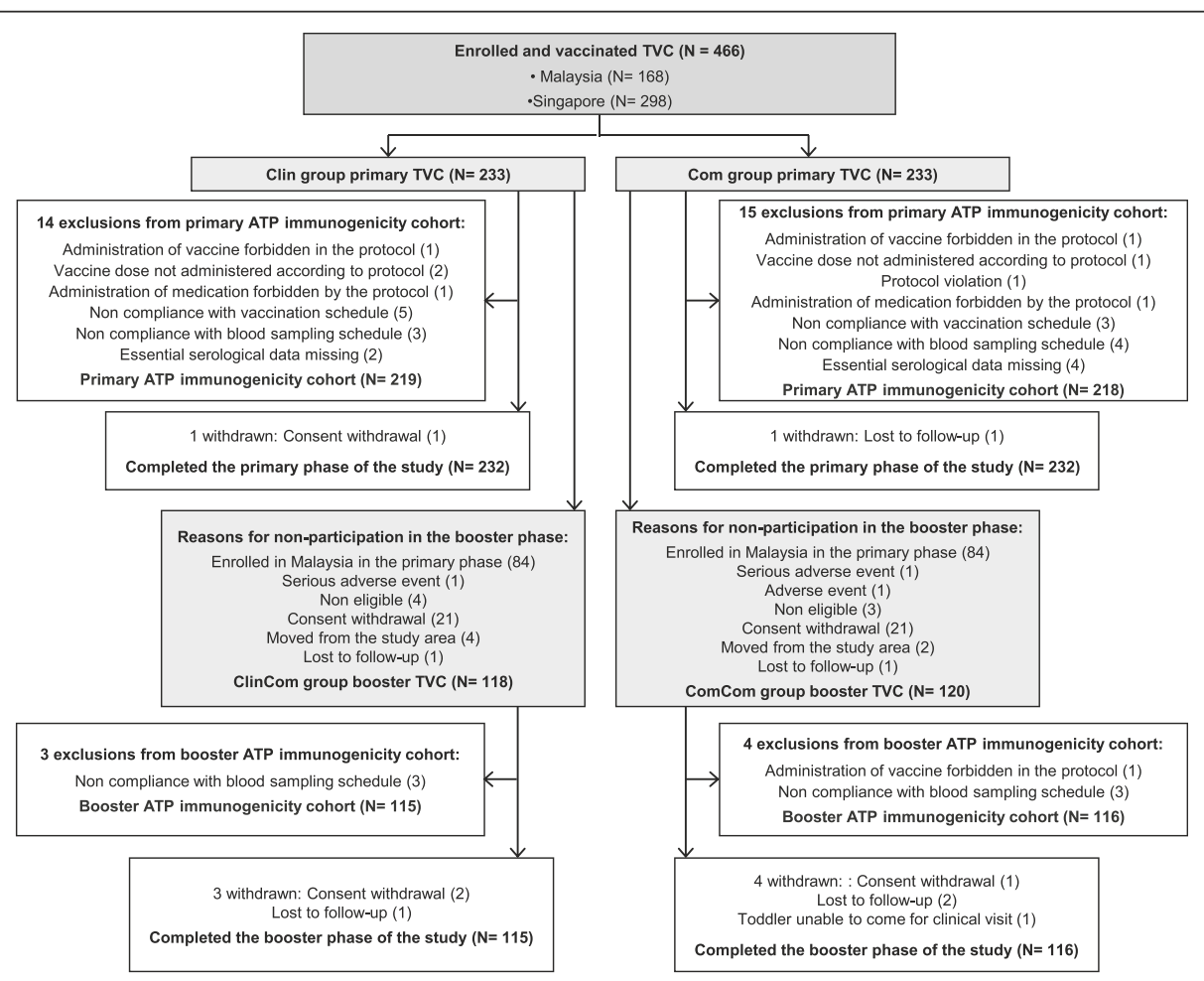

Figure 1 Trial profile. Clin = group of infants from Malaysia and Singapore who received the Phase III Clinical lot of PHiD-CV in the primary vaccination phase. Com = group of infants from Malaysia and Singapore who received the Commercial lot of PHiD-CV in the primary vaccination phase. ClinCom = group of toddlers from Singapore primed with the Phase III Clinical lot of PHiD-CV who received the Commercial lot of PHiD-CV in the booster vaccination phase. ComCom = group of toddlers from Singapore primed with the Commercial lot of PHiD-CV who received the Commercial lot of PHiD-CV in the booster vaccination phase. 
Table 1 Demographic characteristics of the study participants (primary and booster ATP immunogenicity cohorts)

\begin{tabular}{|c|c|c|c|}
\hline \multicolumn{2}{|c|}{ Primary vaccination phase } & \multirow{2}{*}{$\begin{array}{c}\begin{array}{c}\text { Clin group } \\
\mathbf{N}=\mathbf{2 1 9}\end{array} \\
7.3 \pm 1.35\end{array}$} & \multirow{2}{*}{$\begin{array}{c}\begin{array}{c}\text { Com group } \\
\mathbf{N}=\mathbf{2 1 8}\end{array} \\
7.3 \pm 1.31\end{array}$} \\
\hline Age & Mean age \pm SD (weeks) & & \\
\hline & Age range (weeks) & $6-11$ & $6-11$ \\
\hline \multirow[t]{2}{*}{ Gender } & Female n (\%) & $108(49.3)$ & $95(43.6)$ \\
\hline & Male n (\%) & $111(50.7)$ & $123(56.4)$ \\
\hline \multirow[t]{3}{*}{ Race } & Asian - South East Asian heritage n (\%) & $217(99.1)$ & $217(99.5)$ \\
\hline & Asian - Central/South Asian heritage n (\%) & $1(0.5)$ & $0(0.0)$ \\
\hline & Asian - East Asian heritage n (\%) & $1(0.5)$ & $1(0.5)$ \\
\hline \multicolumn{2}{|c|}{ Booster vaccination phase } & $\begin{array}{c}\text { ClinCom group } \\
\quad \mathrm{N}=115\end{array}$ & $\begin{array}{c}\text { ClinCom group } \\
\quad N=116\end{array}$ \\
\hline \multirow[t]{2}{*}{ Age } & Mean age \pm SD (months) & $18.8 \pm 0.84$ & $18.9 \pm 0.85$ \\
\hline & Age range (months) & $18-21$ & $18-21$ \\
\hline \multirow[t]{2}{*}{ Gender } & Female $n(\%)$ & $59(51.3)$ & $48(41.4)$ \\
\hline & Male n (\%) & $56(48.7)$ & $68(58.6)$ \\
\hline \multirow[t]{2}{*}{ Race } & Asian - South East Asian heritage n (\%) & $114(99.1)$ & $115(99.1)$ \\
\hline & Asian - East Asian heritage n (\%) & $1(0.9)$ & $1(0.9)$ \\
\hline
\end{tabular}

ATP = according to protocol.

Clin = group of infants from Malaysia and Singapore who received the Phase III Clinical lot of PHiD-CV in the primary vaccination phase.

$\mathrm{Com}=$ group of infants from Malaysia and Singapore who received the Commercial lot of PHiD-CV in the primary vaccination phase.

ClinCom = group of toddlers from Singapore primed with the Phase III Clinical lot of PHiD-CV who received the Commercial lot of PHiD-CV in the booster vaccination phase.

ComCom $=$ group of toddlers from Singapore primed with the Commercial lot of PHiD-CV who received the Commercial lot of PHiD-CV in the booster vaccination phase.

$\mathrm{N}=$ number of participants.

$\mathrm{n}(\%)=$ number (percentage) of participants with the specified characteristic.

$\mathrm{SD}=$ standard deviation.

Range $=$ minimum - maximum .

be non-inferior to those induced by the Phase III Clinical lot (Figure 2; Additional file 1: Table S1).

One month post-primary vaccination, for each vaccine pneumococcal serotype, $\geq 96.3 \%$ and $\geq 93.6 \%$ of infants had antibody concentrations $\geq 0.2 \mu \mathrm{g} / \mathrm{mL}$ in the Clin and Com groups, respectively (Table 2). Antibody GMCs for serotypes 4 and 5 seemed higher in the Clin group. For each vaccine pneumococcal serotype, percentages of infants with OPA titres $\geq 8$ were $\geq 95.6 \%$ in the Clin group, except for serotype 1 , and $\geq 96.6 \%$ in the Com group, except for serotypes 1 and 6B (Table 3). OPA GMTs for serotype $18 \mathrm{C}$ seemed higher in the Clin group.

For each vaccine pneumococcal serotype, $\geq 71.8 \%$ and $\geq 60.8 \%$ of toddlers at pre-booster vaccination, and $\geq 99.1 \%$ and $\geq 98.2 \%$ of toddlers one month post-booster vaccination, had antibody concentrations $\geq 0.2 \mu \mathrm{g} / \mathrm{mL}$ in the ClinCom and ComCom groups, respectively (Table 4).

One month post-primary vaccination, for cross-reactive serotypes $6 \mathrm{~A}$ and $19 \mathrm{~A}, \geq 60.6 \%$ and $\geq 54.6 \%$ of infants had antibody concentrations $\geq 0.2 \mu \mathrm{g} / \mathrm{mL}$ (Table 2 ), and $\geq 85.5 \%$ and $\geq 37.7 \%$ of infants had OPA titres $\geq 8$, in the ClinCom and ComCom groups, respectively (Table 3 ). One month post-booster vaccination, for each cross-reactive serotype, $\geq 93.4 \%$ of toddlers reached antibody concentrations $\geq 0.2 \mu \mathrm{g} / \mathrm{mL}$ (Table 4).

One month post-primary vaccination, $\geq 99.5 \%$ of infants had measurable anti-protein D antibodies and higher anti-protein D adjusted antibody GMCs were observed in the Clin group (Figure 2). The anti-protein D antibody seropositivity rates were $100 \%$ and $98.3 \%$ of toddlers at pre-booster vaccination, and $100 \%$ and $99.1 \%$ of toddlers at one month post-booster vaccination in the ClinCom and ComCom groups, respectively (data not shown).

\section{Co-administered vaccine antigens}

One month post-primary and post-booster vaccination, all children were seroprotected against diphtheria, tetanus and poliovirus types 1,2 and 3, and all infants were seropositive for antibodies against the three pertussis antigens and polyribosylribitol phosphate from Hib. All infants except one were seroprotected against hepatitis B surface antigen (HBs) at one month post-primary vaccination. Three children had anti-HBs antibody concentrations which were initially measured between 10 and $100 \mathrm{mIU} / \mathrm{mL}$. Out of these 3 children, upon retesting 


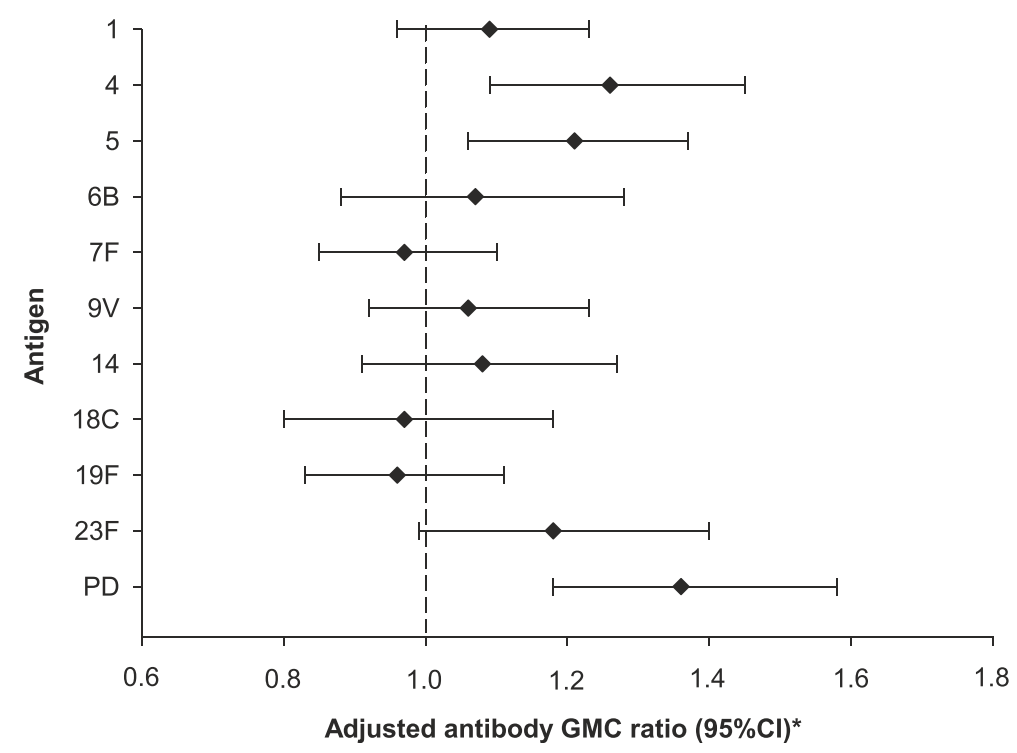

Figure 2 Adjusted antibody GMC ratios between the Clin and the Com groups for the 10 vaccine pneumococcal serotypes and protein D at one month post-primary vaccination (primary ATP immunogenicity cohort). Clin = group of infants from Malaysia and Singapore who received the Phase III Clinical lot of PHiD-CV in the primary vaccination phase. Com = group of infants from Malaysia and Singapore who received the Commercial lot of PHiD-CV in the primary vaccination phase. Adjusted antibody GMC ratio = ratio of the geometric mean concentration at one month post-primary vaccination adjusted for country (pooled variance; Clin over Com group). PD = protein D. 95\% Cl=95\% confidence intervals (represented by the error bars). "Immunological non-inferiority was demonstrated if the upper limit of the $95 \%$ confidence interval of the adjusted antibody GMC ratio (Clin over Com) was below 2.0.

using Immulite, ${ }^{\text {Tw }}$, one was found to be seroprotected while the other 2 had anti-HBs antibody concentrations $<10 \mathrm{mIU} / \mathrm{mL}$. This was further followed up by investigators and one child was subsequently re-vaccinated. Efforts to reach the other child for re-vaccination were unsuccessful. Three months after the second dose of the HRV vaccine, $\geq 81.9 \%$ of infants were seropositive for anti-HRV antibodies (data not shown).

\section{Safety}

In the primary vaccination phase, pain and diarrhoea were the most common overall per dose Grade 3 solicited local and general symptoms, respectively (Figure 3a). Diarrhoea was the most common Grade 3 solicited general symptom considered causally related to vaccination (following 15/698 and 22/698 doses in Clin and Com groups, respectively). Antipyretic use was reported after 296/698 and 276/699 doses, and antipyretics were given prophylactically after 45/698 and 41/699 doses, in the Clin and Com groups, respectively. During 31 days post-vaccination, $113 / 698$ and 119/699 doses were followed by at least one unsolicited $\mathrm{AE}$ in the Clin and Com groups, respectively. The most frequently reported unsolicited AEs were upper respiratory tract infections (35/698 doses) and cough (10/698 doses) in the Clin group, and upper respiratory tract infections (42/699 doses) and pyrexia (7/699 doses) in the Com group. No Grade 3 unsolicited AEs were considered causally related to vaccination. SAEs were reported in 18 and 7 infants in the Clin and Com groups, respectively; none were considered causally related to vaccination and none were fatal.

In the booster vaccination phase, the most common Grade 3 solicited local and general symptoms were pain and irritability, respectively (Figure 3b). Grade 3 solicited general symptoms considered causally related to vaccination were reported in $\leq 4.3 \%$ of toddlers, including Grade 3 fever in one toddler (0.9\%) in each group. Antipyretic use was reported in 50/118 and 66/120 toddlers, and prophylactic antipyretics use in $7 / 118$ and 4/120 toddlers, in the ClinCom and ComCom groups, respectively. Unsolicited AEs were reported in 18/118 and 25/ 120 toddlers in the ClinCom and ComCom groups, respectively. The most frequently reported unsolicited AEs were rhinorrhea (7/118 toddlers) and cough (5/118 toddlers) in the ClinCom group, and upper respiratory tract infections (6/120 toddlers) and rhinorrhea and pyrexia (each in 5/120 toddlers) in the ComCom group. One Grade 3 unsolicited AE considered causally related to vaccination (urticaria) was reported in the ComCom group. Four toddlers in the ComCom group reported SAEs; none were considered causally related to vaccination and none were fatal.

\section{Discussion}

Three primary doses of PHiD-CV given to 2-, 3-, and 5 -month-old infants from Malaysia and Singapore were 
Table 2 Immune responses to pneumococcal polysaccharides at one month post-primary vaccination (primary ATP immunogenicity cohort): 22F-ELISA

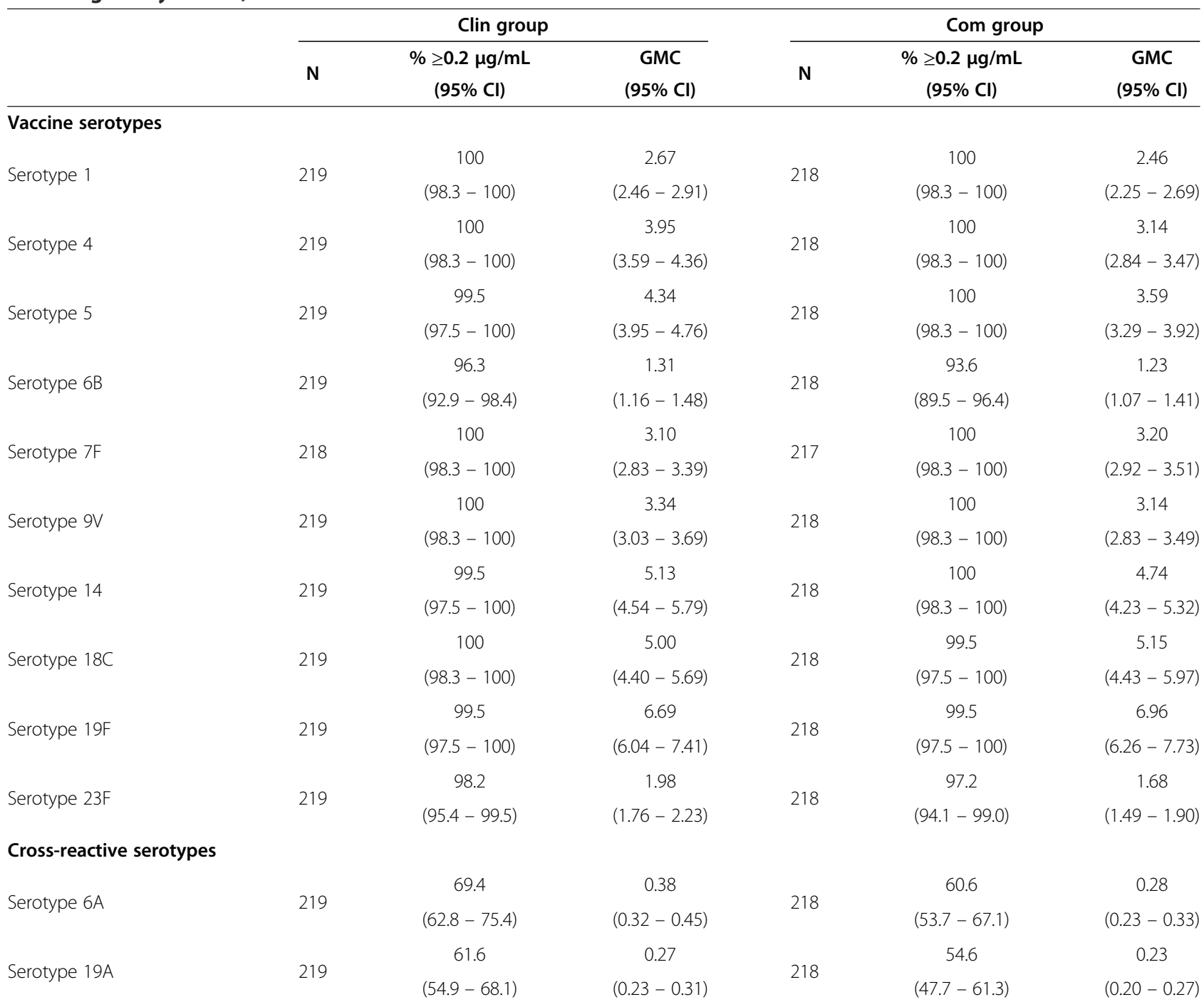

ATP = according to protocol.

Clin = group of infants from Malaysia and Singapore who received the Phase III Clinical lot of PHiD-CV in the primary vaccination phase

$\mathrm{Com}=$ group of infants from Malaysia and Singapore who received the Commercial lot of PHiD-CV in the primary vaccination phase.

$\mathrm{N}=$ number of infants with available results.

$95 \% \mathrm{Cl}=95 \%$ confidence interval.

$\mathrm{GMC}=$ geometric mean concentration .

$\%=$ percentage of infants with antibody concentrations or OPA titres above the specified cut-off.

shown to be immunogenic with a clinically acceptable safety profile. Non-inferiority of the immunogenicity of the PHiD-CV Commercial versus the Phase III Clinical lot was demonstrated for each vaccine pneumococcal serotype and protein D, although antibody GMCs for serotypes 4 and 5 and protein D, and OPA GMTs for serotype $18 \mathrm{C}$, seemed higher in infants who received the Phase III Clinical lot. Nonetheless, as percentages of infants reaching threshold antibody concentrations and OPA titres for vaccine antigens were high and comparable in both groups, the observed differences in immunogenicity may be of limited clinical relevance. For each vaccine pneumococcal serotype, post-primary vaccination antibody GMCs seemed in line with those previously measured in Korea and Taiwan [16,19], and higher than in Europe $[15,18,21]$. Although it remains unclear why the magnitude of immune responses to pneumococcal conjugate vaccines varies in different populations, plausible explanations include genetic factors, early exposure to $S$. pneumoniae, or nasopharyngeal carriage of pneumococcal serotypes [36]. Pre-vaccination antibody concentration, which is influenced by waning 
Table 3 Immune responses to pneumococcal polysaccharides at one month post-primary vaccination (primary ATP immunogenicity cohort): OPA

\begin{tabular}{|c|c|c|c|c|c|c|}
\hline & & Clin g & & & Com g & \\
\hline & $\mathrm{N}$ & $\begin{array}{c}\% \geq 8 \\
(95 \% \mathrm{Cl})\end{array}$ & $\begin{array}{c}\text { GMT } \\
(95 \% \mathrm{Cl})\end{array}$ & N & $\begin{array}{c}\% \geq 8 \\
(95 \% \mathrm{Cl})\end{array}$ & $\begin{array}{c}\text { GMT } \\
(95 \% \mathrm{Cl})\end{array}$ \\
\hline Vaccine serot & & & & & & \\
\hline Seretune 1 & 200 & 88.5 & 128.9 & 210 & 90.0 & 122.1 \\
\hline & & $(83.4-92.5)$ & $(102.7-161.7)$ & 210 & $(85.1-93.7)$ & $(98.3-151.7)$ \\
\hline Seretyen 4 & 207 & 100 & 698.3 & 207 & 98.1 & 609.3 \\
\hline Servery 4 & 201 & $(98.2-100)$ & $(619.6-786.9)$ & 201 & $(95.1-99.5)$ & $(519.6-714.3)$ \\
\hline Corotung 5 & 207 & 98.6 & 127.9 & 210 & 96.7 & 98.6 \\
\hline seroype 3 & 201 & $(95.8-99.7)$ & $(109.0-149.9)$ & 210 & $(93.3-98.6)$ & $(83.0-117.1)$ \\
\hline Soretvine $6 \mathrm{R}$ & 205 & 95.6 & 870.7 & 206 & 92.7 & 619.2 \\
\hline setulype UD & 200 & $(91.8-98.0)$ & $(710.2-1067.6)$ & 200 & $(88.3-95.9)$ & $(483.4-793.2)$ \\
\hline & 206 & 100 & 3905.8 & 208 & 100 & 3585.7 \\
\hline Serotype /F & 200 & $(98.2-100)$ & $(3420.2-4460.4)$ & 200 & $(98.2-100)$ & $(3119.8-4121.2)$ \\
\hline Seretype gy & 207 & 100 & 1800.0 & 208 & 100 & 1851.3 \\
\hline servlype so & & $(98.2-100)$ & $(1596.6-2029.3)$ & 200 & $(98.2-100)$ & $(1612.3-2125.8)$ \\
\hline Soretven 14 & 200 & 99.5 & 1521.0 & 20 & 99.5 & 1485.8 \\
\hline serolype 14 & 209 & $(97.4-100)$ & $(1313.3-1761.6)$ & 200 & $(97.4-100)$ & $(1280.5-1724.0)$ \\
\hline Serotyne 186 & 204 & 99.0 & 533.5 & 206 & 96.6 & 383.9 \\
\hline serorype ioc & 204 & $(96.5-99.9)$ & $(461.8-616.4)$ & 200 & $(93.1-98.6)$ & $(319.3-461.5)$ \\
\hline Serotyne 19F & 206 & 98.1 & 689.6 & 206 & 97.1 & 573.5 \\
\hline serotype igr & 200 & $(95.1-99.5)$ & $(581.1-818.2)$ & 200 & $(93.8-98.9)$ & $(477.2-689.3)$ \\
\hline Serotype 23F & 209 & 99.0 & 2716.7 & 207 & 99.5 & 2379.5 \\
\hline & & $(96.6-99.9)$ & $(2316.3-3186.3)$ & 201 & $(97.3-100)$ & $(2043.4-2770.7)$ \\
\hline Cross-reacting & & & & & & \\
\hline Serotype $6 \mathrm{~A}$ & 197 & 87.8 & 230.8 & 200 & 85.5 & 173.7 \\
\hline & & $(82.4-92.0)$ & $(180.3-295.4)$ & & $(79.8-90.1)$ & $(133.9-225.3)$ \\
\hline Serotype 19A & 197 & 42.1 & 18.1 & 199 & 37.7 & 15.1 \\
\hline serorype i 9 A & 197 & $(35.1-49.4)$ & $(13.7-23.8)$ & 199 & $(30.9-44.8)$ & $(11.5-19.8)$ \\
\hline
\end{tabular}

ATP = according to protocol.

OPA = opsonophagocytic activity

Clin = group of infants from Malaysia and Singapore who received the Phase III Clinical lot of PHiD-CV in the primary vaccination phase.

$\mathrm{Com}=$ group of infants from Malaysia and Singapore who received the Commercial lot of PHiD-CV in the primary vaccination phase.

$\mathrm{N}=$ number of infants with available results.

$95 \% \mathrm{Cl}=95 \%$ confidence interval.

$\mathrm{GMT}=$ geometric mean titre.

$\%=$ percentage of infants with antibody concentrations or OPA titres above the specified cut-off.

maternal antibodies and increasing adaptive immunity due to early exposure to S. pneumoniae, in Asian children was evaluated in a previous study conducted in Taiwan, where for each vaccine pneumococcal serotype the percentage of children with pre-vaccination antibody concentrations $\geq 0.2 \mu \mathrm{g} / \mathrm{ml}$ ranged from $11.5 \%$ to $42.5 \%$, except serotype 14 (61\%) [19]. Vaccine efficacy and effectiveness of pneumococcal conjugate vaccines have been demonstrated in various countries, hence clinical relevance of population differences remains unknown [37-42].

For each vaccine pneumococcal serotype, antibody GMCs calculated before the booster dose administration were lower than those measured one month post-primary vaccination, but $\geq 60.8 \%$ of toddlers from Singapore had pre-booster antibody concentrations $\geq 0.2 \mu \mathrm{g} / \mathrm{mL}$. The booster dose of the PHiD-CV Commercial lot induced a robust immune response; virtually all toddlers reached 
Table 4 Pre- and post-booster immune response to pneumococcal polysaccharides (ATP persistence and booster ATP immunogenicity cohorts)

\begin{tabular}{|c|c|c|c|c|c|c|c|c|c|c|c|c|}
\hline & \multicolumn{6}{|c|}{ ClinCom group } & \multicolumn{6}{|c|}{ ComCom group } \\
\hline & \multicolumn{3}{|c|}{ Pre-booster dose } & \multicolumn{3}{|c|}{ Post-booster dose } & \multicolumn{3}{|c|}{ Pre-booster dose } & \multicolumn{3}{|c|}{ Post-booster dose } \\
\hline & $\mathrm{N}$ & $\begin{array}{c}\% \geq 0.2 \mu \mathrm{g} / \mathrm{mL} \\
(95 \% \mathrm{Cl})\end{array}$ & $\begin{array}{c}\text { GMC } \\
(95 \% \mathrm{Cl})\end{array}$ & $\mathbf{N}$ & $\begin{array}{c}\% \geq 0.2 \mu \mathrm{g} / \mathrm{mL} \\
(95 \% \mathrm{Cl})\end{array}$ & $\begin{array}{c}\text { GMC } \\
(95 \% \mathrm{Cl})\end{array}$ & $\mathrm{N}$ & $\begin{array}{c}\% \geq 0.2 \mu \mathrm{g} / \mathrm{mL} \\
(95 \% \mathrm{Cl})\end{array}$ & $\begin{array}{c}\text { GMC } \\
(95 \% \mathrm{Cl})\end{array}$ & $\mathrm{N}$ & $\begin{array}{c}\% \geq 0.2 \mu \mathrm{g} / \mathrm{mL} \\
(95 \% \mathrm{Cl})\end{array}$ & $\begin{array}{c}\text { GMC } \\
(95 \% \mathrm{Cl})\end{array}$ \\
\hline \multicolumn{13}{|c|}{ Vaccine serotypes } \\
\hline \multirow[t]{2}{*}{ Serotype 1} & 111 & 85.6 & 0.48 & 107 & 100 & 7.14 & 112 & 75.0 & 0.35 & 111 & 100 & 6.29 \\
\hline & & $(77.6-91.5)$ & $(0.40-0.57)$ & & $(96.6-100)$ & $(6.12-8.32)$ & & $(65.9-82.7)$ & $(0.30-0.41)$ & & $(96.7-100)$ & $(5.38-7.35)$ \\
\hline \multirow[t]{2}{*}{ Serotype 4} & 107 & 86.9 & 0.56 & 106 & 100 & 7.53 & 106 & 82.1 & 0.48 & 109 & 100 & 7.43 \\
\hline & & $(79.0-92.7)$ & $(0.48-0.67)$ & & $(96.6-100)$ & $(6.44-8.80)$ & & $(73.4-88.8)$ & $(0.40-0.58)$ & & $(96.7-100)$ & $(6.33-8.71)$ \\
\hline \multirow[t]{2}{*}{ Serotype 5} & 103 & 92.2 & 0.76 & 106 & 100 & 7.91 & 103 & 91.3 & 0.54 & 108 & 100 & 7.16 \\
\hline & & $(85.3-96.6)$ & $(0.65-0.89)$ & & $(96.6-100)$ & $(6.91-9.06)$ & & $(84.1-95.9)$ & $(0.47-0.63)$ & & $(96.6-100)$ & $(6.25-8.20)$ \\
\hline \multirow[t]{2}{*}{ Serotype 6B } & 103 & 71.8 & 0.34 & 106 & 100 & 3.30 & 102 & 60.8 & 0.32 & 109 & 98.2 & 3.12 \\
\hline & & $(62.1-80.3)$ & $(0.29-0.40)$ & & $(96.6-100)$ & $(2.85-3.81)$ & & $(50.6-70.3)$ & $(0.25-0.41)$ & & $(93.5-99.8)$ & $(2.59-3.76)$ \\
\hline \multirow[t]{2}{*}{ Serotype 7F } & 104 & 95.2 & 0.88 & 106 & 100 & 9.02 & 105 & 96.2 & 0.91 & 109 & 100 & 9.25 \\
\hline & & $(89.1-98.4)$ & $(0.75-1.03)$ & & $(96.6-100)$ & $(7.77-10.47)$ & & $(90.5-99.0)$ & $(0.78-1.07)$ & & $(96.7-100)$ & $(8.04-10.64)$ \\
\hline \multirow[t]{2}{*}{ Serotype 9V } & 105 & 98.1 & 0.90 & 107 & 100 & 9.36 & 102 & 94.1 & 0.73 & 109 & 100 & 10.42 \\
\hline & & $(93.3-99.8)$ & $(0.77-1.06)$ & & $(96.6-100)$ & $(8.15-10.75)$ & & $(87.6-97.8)$ & $(0.62-0.85)$ & & $(96.7-100)$ & $(8.94-12.14)$ \\
\hline \multirow[t]{2}{*}{ Serotype 14} & 105 & 93.3 & 1.06 & 106 & 100 & 13.03 & 100 & 93.0 & 0.91 & 106 & 100 & 13.28 \\
\hline & & $(86.7-97.3)$ & $(0.86-1.31)$ & & $(96.6-100)$ & $(10.95-15.50)$ & & $(86.1-97.1)$ & $(0.75-1.11)$ & & $(96.6-100)$ & $(11.06-15.95)$ \\
\hline \multirow[t]{2}{*}{ Serotype $18 C$} & 109 & 92.7 & 0.83 & 106 & 100 & 19.80 & 108 & 92.6 & 0.78 & 108 & 100 & 24.19 \\
\hline & & $(86.0-96.8)$ & $(0.69-1.01)$ & & $(96.6-100)$ & $(17.02-23.03)$ & & $(85.9-96.7)$ & $(0.65-0.93)$ & & $(96.6-100)$ & $(20.66-28.33)$ \\
\hline \multirow[t]{2}{*}{ Serotype 19F } & 103 & 98.1 & 1.10 & 106 & 100 & 19.68 & 103 & 99.0 & 0.96 & 108 & 100 & 20.55 \\
\hline & & $(93.2-99.8)$ & $(0.87-1.40)$ & & $(96.6-100)$ & $(17.22-22.51)$ & & $(94.7-100)$ & $(0.82-1.13)$ & & $(96.6-100)$ & $(17.62-23.98)$ \\
\hline \multirow[t]{2}{*}{ Serotype 23F } & 108 & 83.3 & 0.66 & 107 & 99.1 & 7.19 & 106 & 79.2 & 0.47 & 109 & 100 & 6.83 \\
\hline & & $(74.9-89.8)$ & $(0.51-0.84)$ & & $(94.9-100)$ & $(5.94-8.71)$ & & $(70.3-86.5)$ & $(0.38-0.58)$ & & $(96.7-100)$ & $(5.77-8.07)$ \\
\hline \multicolumn{13}{|c|}{ Cross-reactive serotypes } \\
\hline \multirow[t]{2}{*}{ Serotype 6A } & 109 & 53.2 & 0.23 & 106 & 99.1 & 2.13 & 111 & 45.0 & 0.21 & 108 & 97.2 & 1.99 \\
\hline & & $(43.4-62.8)$ & $(0.18-0.28)$ & & $(94.9-100)$ & $(1.70-2.66)$ & & $(35.6-54.8)$ & $(0.16-0.26)$ & & $(92.1-99.4)$ & $(1.60-2.49)$ \\
\hline \multirow[t]{2}{*}{ Serotype 19A } & 112 & 49.1 & 0.18 & 106 & 93.4 & 2.13 & 109 & 46.8 & 0.19 & 109 & 96.3 & 2.96 \\
\hline & & $(39.5-58.7)$ & $(0.14-0.22)$ & & $(86.9-97.3)$ & $(1.65-2.76)$ & & $(37.2-56.6)$ & $(0.15-0.24)$ & & $(90.9-99.0)$ & $(2.26-3.87)$ \\
\hline
\end{tabular}

ClinCom = group of toddlers from Singapore primed with the Phase III Clinical lot of PHiD-CV who received the Commercial lot of PHiD-CV in the booster vaccination phase.

$\mathrm{ComCom}=$ group of toddlers from Singapore primed with the Commercial lot of PHiD-CV who received the Commercial lot of PHiD-CV in the booster vaccination phase.

$\mathrm{N}=$ number of participants with available results.

$95 \% \mathrm{Cl}=95 \%$ confidence interval.

$\%=$ percentage of infants with antibody concentrations above the specified cut-off.

$\mathrm{GMC}=$ geometric mean concentration. 

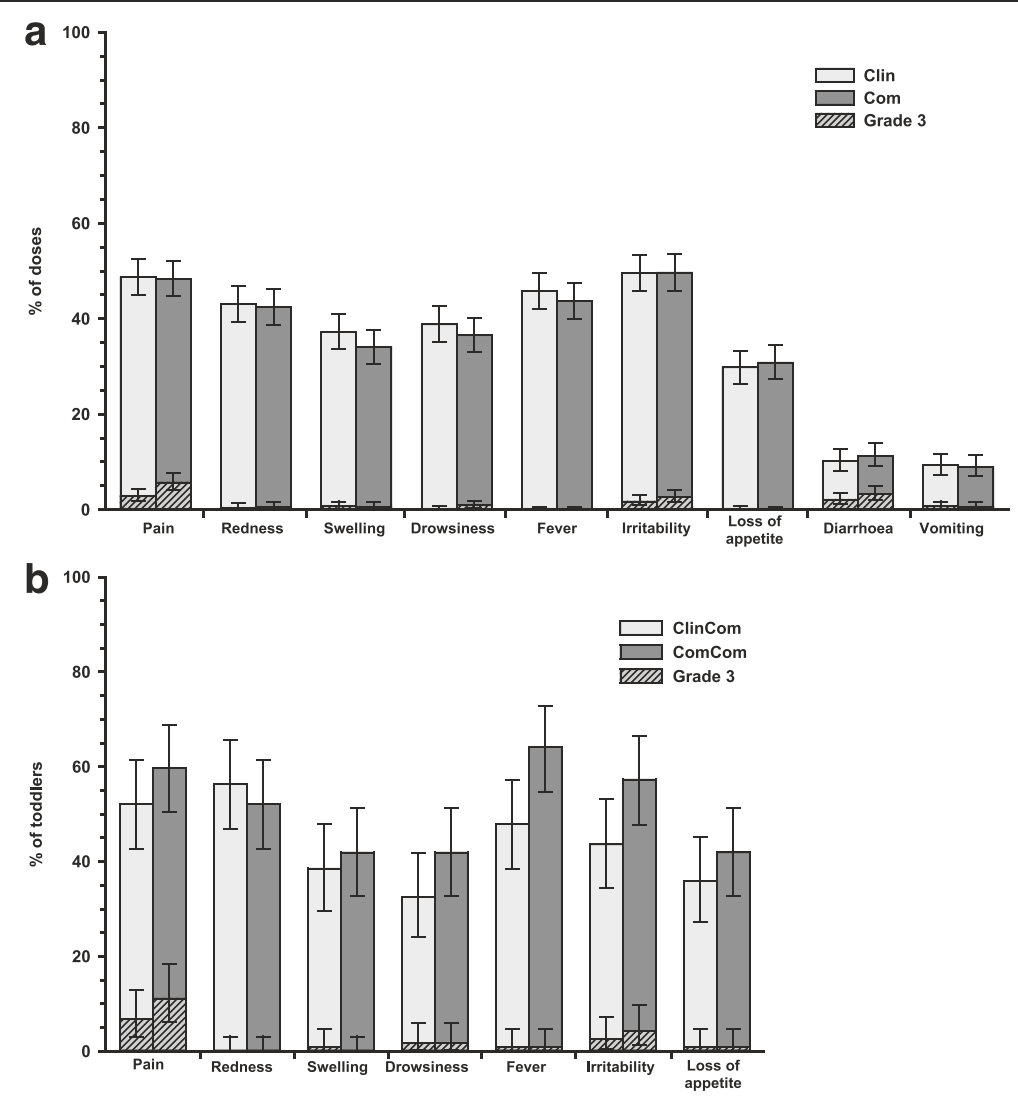

Figure 3 Solicited symptoms following (a) primary vaccination (overall/dose; primary TVC) and (b) booster dose (booster TVC). TVC = total vaccinated cohort. Clin = group of infants from Malaysia and Singapore who received the Phase III Clinical lot of PHiD-CV in the primary vaccination phase. Com = group of infants from Malaysia and Singapore who received the Commercial lot of PHiD-CV in the primary vaccination phase. ClinCom = group of toddlers from Singapore primed with the Phase III Clinical lot of PHiD-CV who received the Commercial lot of PHiD-CV in the booster vaccination phase. ComCom = group of toddlers from Singapore primed with the Commercial lot of PHiD-CV who received the Commercial lot of PHiD-CV in the booster vaccination phase. Error bars represent $95 \%$ confidence intervals. Solicited symptoms are recorded during 4-days post-vaccination.

antibody concentrations $\geq 0.2 \mu \mathrm{g} / \mathrm{mL}$ one month postbooster vaccination and antibody concentrations were higher than those measured post-primary vaccination, which suggested that primary vaccination of infants with PHiD-CV induced immunological memory $[15,16,18,21]$.

Primary vaccination with either vaccine lot and booster vaccination with the PHiD-CV Commercial lot induced immune responses against cross-reactive serotypes $6 \mathrm{~A}$ and 19A. Some functional OPA responses for crossreactive serotype 19A were observed following primary PHiD-CV vaccination, in-line with previous studies $[15,16,18,21]$. However, the level of protection against serotype 19A conferred by the immune response induced by PHiD-CV should be further determined [43,44].

Both PHiD-CV lots induced antibodies against the NTHi protein $\mathrm{D}$ carrier, which could potentially provide protection against disease caused by NTHi. Although a clear correlation between efficacy and anti-protein D antibody concentrations has not been established, efficacy trials with the predecessor 11-valent NTHi protein D-conjugated vaccine and $\mathrm{PHiD}-\mathrm{CV}$ have suggested that the protein $\mathrm{D}$ carrier contributed to the induction of protection against acute otitis media due to NTHi $[45,46]$. The co-administered vaccines given simultaneously with primary or booster doses of PHiD-CV were also immunogenic. This is consistent with other studies and suggests that no clinically relevant interference occurred between PHiD-CV and HRV or DTPa-based vaccines $[17,19]$.

No SAEs considered causally related to vaccination and no fatal SAEs were reported throughout the study. The reactogenicity and safety profiles of the Commercial and the Phase III Clinical lots of PHiD-CV were comparable and clinically acceptable, in line with previous studies [20].

The primary vaccination phase was powered to demonstrate the primary objectives. Other comparisons should be considered cautiously, since there was no adjustment for multiple comparisons of the various endpoints. The clinical relevance of the observed differences remains unknown, especially for antigens with no correlate of 
protection. The booster vaccination phase was also limited by its open design.

\section{Conclusions}

This study showed that different lots of PHiD-CV were immunogenic with a clinically acceptable safety profile when given as 3-dose primary vaccination in 2-, 3- and 5 -month-old infants from Malaysia and Singapore. A booster dose of the PHiD-CV Commercial lot induced a robust immune response in 18-21 month-old toddlers from Singapore. Both PHiD-CV lots were administered with other paediatric vaccines without compromising their immune response.

Synflorix, Infanrix-IPV/Hib, and Infanrix hexa are trademarks of the GlaxoSmithKline group of companies.

\section{Additional file}

Additional file 1: Between groups adjusted antibody GMC ratios post-primary vaccination (primary ATP immunogenicity cohort).

\section{Abbreviations}

AE: Adverse event; ANOVA: Analysis of variance; ATP: According to protocol: Cl: Confidence interval; DTPa-HBV-IPV/Hib: Diphtheria, tetanus, acellular pertussis-hepatitis B virus-inactivated poliovirus, and $H$. influenzae type $b$ vaccine; ELISA: Enzyme-linked immunosorbent assay; GMC: Geometric mean concentration; GMT: Geometric mean titre; HRV: Human rotavirus; IPD: Invasive pneumococcal disease; OPA: Opsonophagocytic activity PHiD-CV: Pneumococcal non-typeable Haemophilus influenzae (NTHi) protein D conjugate vaccine; SAE: Serious adverse event.

\section{Competing interests}

CYC declared having received grants from GlaxoSmithKline Biologicals SA for research coordination, clinics, and vaccines. MTK and FSL declared having received grants for carrying out the reported study and other studies and travel fees for presenting the study results at conferences. PCC received payment for giving talks on vaccination to doctors and nurses and for travelling to a conference. CYC received payment for training workshop lectures and for travelling to a conference. MTK received honorarium as speaker at meetings organised by the Malaysian Paediatric Association. KKT received reimbursement for travelling expenses to attend investigators meeting for trial initiation. YWSY had no competing interest. DB, FS, YLT were employed by GlaxoSmithKline Vaccines during the study period. KS and $\mathrm{MH}$ worked as consultant for GlaxoSmithKline Vaccines. DB declared stock options ownership in GlaxoSmithKline Vaccines.

\section{Authors' contributions}

Study design was done by FSL, MTK, KKT, YLT, KS and DB. Recruitment of centres and/or investigators was done by FSL, PCC, MTK, YLT, CYC, whereas provision of subjects by FSL, PCC, MTK, KKT, YLT, YWSY and CYC. Performing or supervising the analysis was done by PCC, FS, YLT, MH, DB and interpretation of results by FS, KKT, MH, YLT, KS and DB. Supervision of the study/research group was done by PCC, MTK, KT, YLT, KS, YWSY, DB and CYC. Acquisition of funding by KKT, YLT and DB. All authors read and approved the final manuscript.

\section{Acknowledgements}

The authors thank the children and their parents/legally acceptable representatives who participated in the study, the study nurses, and other staff members without whom this study would not have been possible. The authors also thank Dr Tan Kim Kiat for his contribution to the study, Josephine Tan Liu, Natalie Tan Woon Hui, and Thoon Koh Cheng for their involvement in recruitment and follow-ups of patients. We are grateful to all teams of GlaxoSmithKline Vaccines for their contribution to this study, especially Aurelie Fanic for statistical input to protocol and primary phase analysis, Sudheer Ravula and Nancy François for performing statistical analyses for booster phase and quality check, and Liliana Manciu, Marta Moreira and Tineke Ryckaert for their contribution to the study. The authors also thank Aneta Skwarek-Maruszewska and Bart van Heertum (XPE Pharma \& Science, Belgium c/o GlaxoSmithKline Vaccines) for publication management and Claire Verbelen (XPE Pharma \& Science, Belgium) for drafting the manuscript.

\section{Role of the funding source}

GlaxoSmithKline Biologicals SA was the funding source and was involved in all stages of the study conduct and analysis. GlaxoSmithKline Biologicals SA also took responsibility for all costs associated with the development and publishing of the present manuscript.

\section{Previous publications}

The results of this study were presented in part at the 32nd Annual Congress of the Malaysian Paediatric Association (MPA), October 15-17, 2010 and at the 14th Asia Pacific Congress of Pediatrics (APCP), September 8-12, 2012.

\section{Author details}

${ }^{1}$ National Healthcare Group Polyclinics, 3 Fusionopolis Link \#03-08, Nexus@one-north, Singapore 138543, Singapore. ²Departement of Pediatrics, University Malaya Medical Centre, Jalan University, 59100 Kuala Lumpur, Malaysia. ${ }^{3}$ Departement of Pediatrics, Tuanku Ja'afar Hospital, Jalan Rasah, 70300 Seremban, Negeri Sembilan, Malaysia. ${ }^{4}$ University Children's Medical Institute, National University Hospital, Singapore 119260, Singapore. ${ }^{5}$ KK Women and Children's Hospital, 100 Bukit Timah Road, Singapore 229899, Singapore. ${ }^{6}$ GlaxoSmithKline Vaccines, 150 Beach Road, \#22-00, Gateway West, Singapore 189720, Singapore. ${ }^{7}$ Current affiliation: Goal Consultancy Asia Pacific, Singapore, Singapore. ${ }^{8}$ GlaxoSmithKline Pharmaceuticals, 5 Embassy Links, SRT Road, Bangalore 560 052, India. ${ }^{9}$ Vaccine Discovery and Development, GlaxoSmithKline Vaccines, 20 Avenue Fleming, 1300 Wavre, Belgium

Received: 26 May 2014 Accepted: 18 September 2014 Published: 2 October 2014

\section{References}

1. O'Brien KL, Wolfson LJ, Watt JP, Henkle E, Deloria-Knoll M, McCall N, Lee E, Mulholland K, Levine OS, Cherian T: Burden of disease caused by Streptococcus pneumoniae in children younger than 5 years: global estimates. Lancet 2009, 374:893-902.

2. Scott JA: The preventable burden of pneumococcal disease in the developing world. Vaccine 2007, 25:2398-2405.

3. Bravo LC: Overview of the disease burden of invasive pneumococcal disease in Asia. Vaccine 2009, 27:7282-7291.

4. Lin TY, Shah NK, Brooks D, Garcia CS: Summary of invasive pneumococcal disease burden among children in the Asia-Pacific region. Vaccine 2010, 28:7589-7605.

5. Jauneikaite $\mathrm{E}$, Jefferies JM, Hibberd ML, Clarke SC: Prevalence of Streptococcus pneumoniae serotypes causing invasive and non-invasive disease in South East Asia: a review. Vaccine 2012, 30:3503-3514.

6. Thoon KC, Chong CY, Tee NW: Early impact of pneumococcal conjugate vaccine on invasive pneumococcal disease in Singapore children, 2005 through 2010. Int J Infect Dis 2012, 16:e209-e215.

7. Suhaimi M, Asmiati AH, Soo TL: Pneumococcal meningitis in children aged 2-60 months at Queen Elizabeth (QE) Hospital, Sabah, Malaysia: before and after the introduction of Hemophilus influenza type b vaccination, Presented at: 5th World Congress of the World Society for Pediatric Infectious Diseases (WSPID). Bangkok, Thailand; 2007.

8. Yasin RM, Zin NM, Hussin A, Nawi SH, Hanapiah SM, Wahab ZA, Raj G, Shafie N, Peng NP, Chu KK, Aziz MN, Maning N, Mohamad JS, Benjamin A, Salleh MA, Zahari SS, Francis A, Ahmad N, Karunakaran R: Current trend of pneumococcal serotypes distribution and antibiotic susceptibility pattern in Malaysian hospitals. Vaccine 2011, 29:5688-5693.

9. Soh SW, Poh CL, Lin RV: Serotype distribution and antimicrobial resistance of Streptococcus pneumoniae isolates from pediatric patients in Singapore. Antimicrob Agents Chemother 2000, 44:2193-2196.

10. Song JH, Jung SI, Ko KS, Kim NY, Son JS, Chang HH, Ki HK, Oh WS, Suh JY, Peck KR, Lee NY, Yang Y, Lu Q, Chongthaleong A, Chiu CH, Lalitha MK, Perera J, Yee T, Kumarasinghe G, Jamal F, Kamarulzaman A, Parasakthi N, Van PH, Carlos C, So T, Ng TK, Shibl A: High prevalence of antimicrobial 
resistance among clinical Streptococcus pneumoniae isolates in Asia (an ANSORP study). Antimicrob Agents Chemother 2004, 48:2101-2107.

11. Chong CY, Koh-Cheng T, Yee-Hui M, Nancy TW: Invasive pneumococcal disease in Singapore children. Vaccine 2008, 26:3427-3431.

12. Vasoo S, Singh K, Hsu LY, Chiew YF, Chow C, Lin RT, Tambyah PA: Increasing antibiotic resistance in Streptococcus pneumoniae colonizing children attending day-care centres in Singapore. Respirology 2011, 16:1241-1248.

13. Le CF, Palanisamy NK, Mohd Yusof MY, Sekaran SD: Capsular serotype and antibiotic resistance of Streptococcus pneumoniae isolates in Malaysia. PLoS One 2011, 6:e19547.

14. Nathan JJ, Taib NM, Desa MN, Masri SN, Yasin R, Jamal F, Sagineedu SR, Karunanidhi A: Prevalence of macrolide resistance and in vitro activities of six antimicrobial agents against clinical isolates of Streptococcus pneumoniae from a multi-center surveillance in Malaysia. Med J Malaysia 2013, 68:119-124.

15. Bermal N, Szenborn L, Chrobot A, Alberto E, Lommel P, Gatchalian S, Dieussaert I, Schuerman L: The 10-valent pneumococcal non-typeable Haemophilus influenzae protein D conjugate vaccine (PHiD-CV) coadministered with DTPW-HBV/Hib and poliovirus vaccines: assessment of immunogenicity. Pediatr Infect Dis J 2009, 28:S89-S96.

16. Kim CH, Kim JS, Cha SH, Kim KN, Kim JD, Lee KY, Kim HM, Kim JH, Hyuk S, Hong JY, Park SE, Kim YK, Kim NH, Fanic A, Borys D, Ruiz-Guinazu J, Moreira M, Schuerman L, Kim KH: Response to primary and booster vaccination with 10-valent pneumococcal nontypeable Haemophilus influenzae protein D conjugate vaccine in Korean infants. Pediatr Infect Dis J 2011 30:e235-e243.

17. Knuf M, Szenborn L, Moro M, Petit C, Bermal N, Bernard L, Dieussaert I, Schuerman L: Immunogenicity of routinely used childhood vaccines when coadministered with the 10-valent pneumococcal non-typeable Haemophilus influenzae protein D conjugate vaccine (PHiD-CV). Pediatr Infect Dis J 2009, 28:S97-S108.

18. Wysocki J, Tejedor JC, Grunert D, Konior R, Garcia-Sicilia J, Knuf M, Bernard L, Dieussaert I, Schuerman L: Immunogenicity of the 10-valent pneumococcal non-typeable Haemophilus influenzae protein D conjugate vaccine (PHiD-CV) when coadministered with different Neisseria meningitidis serogroup C conjugate vaccines. Pediatr Infect Dis J 2009, 28:S77-S88.

19. Lin TY, Lu CY, Chang LY, Chiu CH, Huang YC, Bock HL, Tang H, François N, Moreira M, Schuerman L, Huang LM: Immunogenicity and safety of 10-valent pneumococcal non-typeable Haemophilus influenzae protein $\mathrm{D}$-conjugate vaccine (PHiD-CV) co-administered with routine childhood vaccines in Taiwan. J Formos Med Assoc 2012, 111:495-503.

20. Chevallier B, Vesikari T, Brzostek J, Knuf M, Bermal N, Aristegui J, Borys D, Cleerbout J, Lommel P, Schuerman L: Safety and reactogenicity of the 10-valent pneumococcal non-typeable Haemophilus influenzae protein D conjugate vaccine (PHiD-CV) when coadministered with routine childhood vaccines. Pediatr Infect Dis J 2009, 28:S109-S118.

21. Vesikari T, Wysocki J, Chevallier B, Karvonen A, Czajka H, Arsène JP, Lommel P, Dieussaert I, Schuerman L: Immunogenicity of the 10-valent pneumococcal non-typeable Haemophilus influenzae protein D conjugate vaccine (PHiD-CV) compared to the licensed 7vCRM vaccine. Pediatr Infect Dis J 2009, 28:S66-S76.

22. Lalwani S, Chatterjee S, Chhatwal J, Verghese VP, Mehta S, Shafi F, Borys D, Moreira M, Schuerman L: Immunogenicity, safety, and reactogenicity of the 10-valent pneumococcal non-typeable Hemophilus influenzae protein $\mathrm{D}$ conjugate vaccine (PHiD-CV) when co-administered with the DTPW-HBV/Hib vaccine in Indian infants: a single-blind, randomized, controlled study. Hum Vaccin Immunother 2012, 8:612-622.

23. Bakaletz LO, Kennedy BJ, Novotny LA, Duquesne G, Cohen J, Lobet Y: Protection against development of otitis media induced by nontypeable Haemophilus influenzae by both active and passive immunization in a chinchilla model of virus-bacterium superinfection. Infect Immun 1999, 67:2746-2762

24. Concepcion NF, Frasch CE: Pneumococcal type $22 \mathrm{~F}$ polysaccharide absorption improves the specificity of a pneumococcal-polysaccharide enzyme-linked immunosorbent assay. Clin Diagn Lab Immunol 2001, 8:266-272.

25. Henckaerts I, Goldblatt D, Ashton L, Poolman J: Critical differences between pneumococcal polysaccharide enzyme-linked immunosorbent assays with and without $22 \mathrm{~F}$ inhibition at low antibody concentrations in pediatric sera. Clin Vaccine Immunol 2006, 13:356-360.

26. Poolman JT, Frasch CE, Kayhty H, Lestrate P, Madhi SA, Henckaerts I: Evaluation of pneumococcal polysaccharide immunoassays using a $22 \mathrm{~F}$ adsorption step with serum samples from infants vaccinated with conjugate vaccines. Clin Vaccine Immunol 2010, 17:134-142.

27. Romero-Steiner S, Frasch CE, Carlone G, Fleck RA, Goldblatt D, Nahm MH: Use of opsonophagocytosis for serological evaluation of pneumococcal vaccines. Clin Vaccine Immunol 2006, 13:165-169.

28. Henckaerts I, Durant N, De Grave D, Schuerman L, Poolman J: Validation of a routine opsonophagocytosis assay to predict invasive pneumococcal disease efficacy of conjugate vaccine in children. Vaccine 2007, 25:2518-2527.

29. Granstrom M, Thoren M, Blennow M, Tiru M, Sato Y: Acellular pertussis vaccine in adults: adverse reactions and immune response. Eur $J$ Clin Microbiol 1987, 6:18-21.

30. Camargo ME, Silveira L, Furuta JA, Oliveira EP, Germek OA Immunoenzymatic assay of anti-diphtheric toxin antibodies in human serum. J Clin Microbiol 1984, 20:772-774.

31. Melville-Smith ME, Seagroatt VA, Watkins JT: A comparison of enzyme-linked immunosorbent assay (ELISA) with the toxin neutralization test in mice as a method for the estimation of tetanus antitoxin in human sera. $J$ Biol Stand 1983, 11:137-144.

32. Karpinski KF, Hayward S, Tryphonas H: Statistical considerations in the quantitation of serum immunoglobulin levels using the enzyme-linked immunosorbent assay (ELISA). J Immunol Methods 1987, 103:189-194.

33. World Health Organization: Progress in the control of viral hepatitis: memorandum from a WHO meeting. Bull World Health Organ 1988, 66:443-455.

34. Hepatitis B virus: a comprehensive strategy for eliminating transmission in the United States through universal childhood vaccination. Recommendations of the Immunization Practices Advisory Committee (ACIP). MMWR Recomm Rep 1991, 40:1-25.

35. World Health Organization: Standard Procedures for Determining Immunity to Poliovirus using the Microneutralization Test (WHO/EPI/GEN 93.9). 1993.

36. Puumalainen T, Dagan R, Wuorimaa T, Zeta-Capeding R, Lucero M, Oligren J, Kayhty $H$, Nohynek $H$ : Greater antibody responses to an eleven valent mixed carrier diphtheria- or tetanus-conjugated pneumococcal vaccine in Filipino than in Finnish or Israeli infants. Pediatr Infect Dis J 2003, 22:141-149.

37. Black SB, Shinefield HR, Ling S, Hansen J, Fireman B, Spring D, Noyes J, Lewis E, Ray P, Lee J, Hackell J: Effectiveness of heptavalent pneumococcal conjugate vaccine in children younger than five years of age for prevention of pneumonia. Pediatr Infect Dis J 2002, 21:810-815.

38. Cutts FT, Zaman SM, Enwere G, Jaffar S, Levine OS, Okolo JB, Oluwalana C, Vaughan A, Obaro SK, Leach A, McAdam KP, Biney E, Saaka M, Onwuchekwa U, Yallop F, Pierce NF, Greenwood BM, Adegbola RA: Efficacy of nine-valent pneumococcal conjugate vaccine against pneumonia and invasive pneumococcal disease in The Gambia: randomised, double-blind, placebo-controlled trial. Lancet 2005, 365:1139-1146.

39. Klugman KP, Madhi SA, Huebner RE, Kohberger R, Mbelle N, Pierce N: A tria of a 9-valent pneumococcal conjugate vaccine in children with and those without HIV infection. N Engl J Med 2003, 349:1341-1348.

40. Lucero MG, Nohynek H, Williams G, Tallo V, Simoes EA, Lupisan S, Sanvictores D, Forsyth S, Puumalainen T, Ugpo J, Lechago M, de Campo M, Abucejo-Ladesma E, Sombrero L, Nissinen A, Soininen A, Ruutu P, Riley I, Makela HP: Efficacy of an 11-valent pneumococcal conjugate vaccine against radiologically confirmed pneumonia among children less than 2 years of age in the Philippines: a randomized, double-blind, placebo-controlled trial. Pediatr Infect Dis J 2009, 28:455-462.

41. Whitney CG, Pilishvili T, Farley MM, Schaffner W, Craig AS, Lynfield R, Nyquist AC, Gershman KA, Vazquez M, Bennett NM, Reingold A, Thomas A, Glode MP, Zell ER, Jorgensen JH, Beall B, Schuchat A: Effectiveness of seven-valent pneumococcal conjugate vaccine against invasive pneumococcal disease: a matched case-control study. Lancet 2006, 368:1495-1502.

42. Palmu AA, Jokinen J, Borys D, Nieminen $H$, Ruokokoski $E$, Siira L, Puumalainen T, Lommel P, Hezareh M, Moreira M, Schuerman L, Kilpi TM: Effectiveness of the ten-valent pneumococcal Haemophilus influenzae protein D conjugate vaccine (PHiD-CV10) against invasive pneumococcal disease: a cluster randomised trial. Lancet 2013, 381:214-222.

43. Deceuninck $G$, De Wals P: Effectiveness of three pneumococcal conjugate vaccines (PCVS) to prevent invasive pneumococcal disease (IPD) in Quebec, Canada [abstract]. Pneumonia 2014, 3:163.

44. Domingues CMAS, Verani JR, Montenegro Renoiner El, Brandileone MCC, Flannery B, De Oliveira LH, Santos JB, De Moraes JC: Effectiveness of ten-valent 
pneumococcal conjugate vaccine against invasive pneumococcal disease in Brazil: a matched case-control study. Lancet Respir Med 2014, 2:464-471.

45. Prymula R, Peeters P, Chrobok V, Kriz P, Novakova E, Kaliskova E, Kohl I, Lommel P, Poolman J, Prieels J-P, Schuerman L: Pneumococcal capsular polysaccharides conjugated to protein $\mathrm{D}$ for prevention of acute otitis media caused by both Streptococcus pneumoniae and non-typable Haemophilus influenzae: a randomised double-blind efficacy study. Lancet 2006, 367:740-748.

46. Tregnaghi MW, Saez Llorens X, Lopez P, Abate H, Smith E, Pósleman A Calvo A, Wong D, Cortes Barbosa C, Ceballos A, Tregnaghi M, Sierra A, Rodriguez M, Troitiño M, Carabajal C, Falaschi A, Leandro A, Castrejon MM, Lepetic A, Lommel P, Hausdorff WP, Borys D, Guiñazú JR, Ortega Barría E, Yarzabal JP, Schuerman L, on behalf of the COMPAS Group: Efficacy of pneumococcal nontypable Haemophilus influenzae protein $D$ conjugate vaccine (PHiD-CV) in young Latin American children: A double-blind randomized controlled trial. PLoS Med 2014, 11:e1001657.

doi:10.1186/1471-2334-14-530

Cite this article as: Lim et al:: A randomised trial to evaluate the immunogenicity, reactogenicity, and safety of the 10-valent pneumococcal non-typeable Haemophilus influenzae protein D conjugate vaccine (PHiD-CV) co-administered with routine childhood vaccines in Singapore and Malaysia. BMC Infectious Diseases 2014 14:530.

\section{Submit your next manuscript to BioMed Central and take full advantage of:}

- Convenient online submission

- Thorough peer review

- No space constraints or color figure charges

- Immediate publication on acceptance

- Inclusion in PubMed, CAS, Scopus and Google Scholar

- Research which is freely available for redistribution 